\title{
An Actor Ratiocinates
}

\author{
Michael Joseph Long \\ Cedar Rapids, IA
}

Bachelor of Arts, Luther College, 1998

A Thesis presented to the Graduate Faculty

of the University of Virginia in Candidacy for the Degree of Master of Fine Arts

Department of Drama

University of Virginia

May, 2014 


\section{TABLE OF CONTENTS}

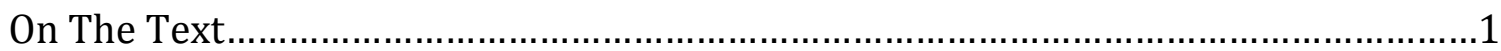

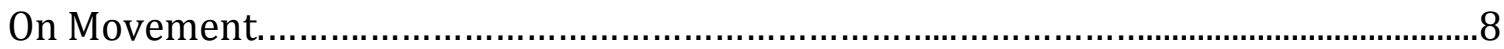

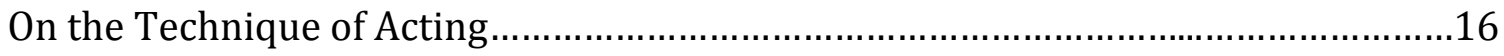

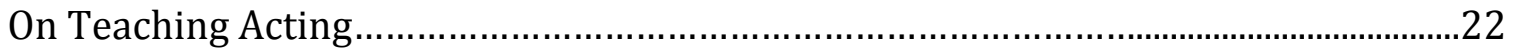

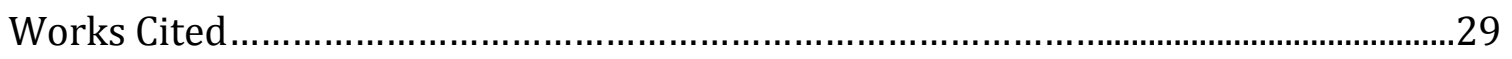

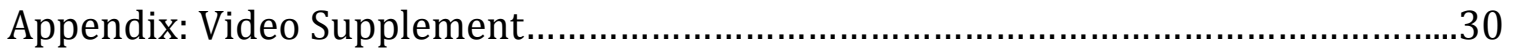


On the Text:

Tapping into the "Aquifer of Impulse"

Or

"Re-Reversed, Comingled Ratiocination"

Shakespeare's characters, how low soever the matter, hope in God for high words ... as should any actor. Luckily the characters (and the actors) have such words: Shakespeare wrote them down. For Shakespeare's, as well as many other playwrights', characters are nothing short of rhetorical geniuses. They wield language that contains and conveys a nearly incomprehensible scope of ideas, emotions, and human expression, and they do it all quite naturally, utilizing a heightened version of the most human of activities: Thought.

A word does not start as a word - it is an end product which begins as an impulse, stimulated by attitude and behavior which dictate the need for expression. This process occurs inside the dramatist; it is repeated inside the actor. Both may only be conscious of the words, but both for the author and then for the actor the word is a small visible portion of a gigantic unforeseen formation.

\section{Peter Brook, The Empty Space (12-13)}

Shakespeare and, indeed, all playwrights, give actors the spoken words and often the physical action which are the "small visible portion" of the ideas and feelings that characters know and experience. Actors are given the final product: the manifestation of some of the impulses that the characters feel (other impulses may not manifest as words or written actions or even in any way at all, and yet may 
still be implied in the words, waiting to be discovered as an actor explores the text.) Shakespeare, as dramatist, constructed the language by drawing upon the "gigantic unforeseen formation" of impulse and its contributors-intention, relationship, circumstances, etcetera-that he and his characters understood so well. His characters speak as a result of impulses generated below the surface of the words. Put another way, Shakespeare's text is like a topographical map. He shows actors the landscape, the rhetorical hills and rivers of rhyme. Actors see on the page words, the final product that the dramatist has given them. These words are the topography of the meaning of the text. They are the lakes and the springs, the "small visible portion" of the "gigantic unforeseen" Aquifer of Impulse, the term I use to describe that which is the actor's understanding of the meaning embedded in the character's words and given actions. It is comprised of the sum total of the character's intentions and emotions; their ideas and thoughts and impulses: everything that lies beneath the surface of a character's words and actions, as understood by the actor. The Aquifer of Impulse.

The job of the actor, as Brook suggests, is to personally inhabit, embody and speak the text in order to discern the underlying meaning that playwrights build into the writing (and the meaning that the characters, being the people who speak those words, inherently understand). In creating a role, an actor is attempting to: 1 ) access and define the boundaries and content of Brook's "gigantic unforeseen formation," the Aquifer of Impulse and, 2) allow the words to manifest anew from these impulses. To establish an understanding of the nature and content of any particular character's Aquifer, actors must utilize the text of the play, which in most 
cases means the character's words-the words themselves in every sense: the meanings and connotations, the sounds, the poetic form, the sentence structure and rhetorical devices - to discern the impulses. To understand from where and wherefore the words are coming, actors must first explore the topography, the landscape of the manifestation of impulse, the portion of the impulse provided by the playwright: the words.

How might the exploration of words lead to the Aquifer of Impulse? Shakespeare's characters, like all people, create their ideas in the moment. As they speak and live in their world, they are forever thinking their way through their ideas, and are constantly experiencing impulses generated by the circumstances of the play, by their own words and actions, and by those of the characters around them. In the course of the script, some of these impulses make their way up from the Aquifer and manifest on the topographical map as written words.

Andrew Wade, the former head of voice for the Royal Shakespeare Company, related to me a possibly apocryphal statement from Oscar Wilde which asks, "How do I know what I think until I hear what I say?" a query that Shakespeare's characters might well have asked. The characters are constantly thinking through a precise, logical train of thought, ratiocinating with every word; each of the manifestations of thought that are written on the page originate in real time in the mind of the character. They are the readily perceivable portion of the streams of thought, the vast lakes of ideas, the manifestation of impulses and thought. And in many cases, as Wade implies, the words, even at the instant they are spoken, are informing the character's thoughts and are often not only the manifestation of 
thought, but are even the origin or catalyst of thought: the spoken words and the thoughts are comingled so that they are inextricably linked and simultaneously informing one another. The actors' task, then, is to utilize vocal acting techniques to explore the words, the manifestations of impulse, to reveal to themselves the character's impulses; to discover the nature of the character's Aquifer.

In order to do this, an actor must first reverse the ratiocinative process that a character experiences while the character speaks his or her text. By speaking the words, the actor begins to feel the impulses that summon the words. Only by means of a thorough, pointed, personal experiencing of speaking the words can an actor begin to comprehend what a character is experiencing and thinking: his or her ratiocination. Great dramatists such as Shakespeare have provided the vast, detailed landscape by which to discover the Aquifer of Impulse. And skilled actors utilize a variety of vocal techniques to explore that landscape aloud. Through repeated, spoken exploration of a text, an actor can discover the impulses behind a character's words. This in-depth exploration is founded in the vocal training and technique of each individual actor and allows each individual to develop a profound, personal connection to the text. By speaking the text aloud the discerning actor will discover in the written landscape the rhetorical details that allow him or her to tap into the Aquifer so that the actor's comprehension of the character's thought process will manifest in his or her body and voice during a performance and thereby lead the audience on a detailed, thoughtful exploration of the terrain.

By beginning with the spoken words, which are the final product of the impulses, an actor works through the thought processes of the character so that the 
understanding, the relationship with the words, the ratiocination, and the Aquifer, of the actor meld with and become that of the character and vice versa. An actor makes the character's ratiocination his or her own ratiocination, and through this process an actor has reverse-ratiocinated the text. The actor has reverse engineered the thoughts of the character by deducing, by way of speaking his or her words, the precise thought process of the character.

The next step for an actor is to then experience the character's thought process during performances so that the actor is thinking, ratiocinating, as the character. In effect, the actor has re-reversed the ratiocinative process: the actor has taken the reversed (deduced) thought process of the character, which was developed in the spoken text exploration, and re-reversed it so that both the actor and the character are ratiocinating — thinking the thoughts and feeling the impulses-in real time during a performance. Hence Re-Reversed Ratiocination.

However, because of the fluid relationship between words and thoughts, as considered by Brook and Wade, Re-Reversed Ratiocination is an incomplete description of the process of performing a text. Because the words are informing the character and the actor in real time as they are spoken, the words and the thoughts and impulses comingle, which modifies the thoughts and impulses and even generates new ones. In effect, the actor's voice is both guiding and guided by the thoughts and impulses of the actor/character. Therefore, the act of performing a text can be described as "Re-Reversed, Comingled Ratiocination." An actor, by drawing upon the vast Aquifer of Impulse, thinks the thoughts of the character and the fire-new words emerge not as a scripted text, but as the manifestation of 
impulse, with ease, with no less celerity than that of thought.

In my own work at the University of Virginia I have studied many vocal acting techniques that have collectively served as the foundation and catalyst for my understanding of acting as Re-Reversed, Comingled Ratiocination. One particularly valuable technique for me is the practice of chanting words slowly on a single pitch and at a consistent volume. Chanting a line of dialogue inherently imposes certain constraints, which provide numerous opportunities to discover the meaning of a text. First, because chanting is slower than an actor would normally attempt to speak a line, an actor is forced to truly consider the meaning and implications of every word -in fact, every syllable and sound—without being able to gloss over words or to settle for a generalized understanding of the meaning of a line. Second, because chanting is done on only a single pitch and consistent volume, it prevents an actor from imposing any particular inflection on the line. When chanted, the line is devoid of pitch inflection and volume variation, which would otherwise inherently impose meaning and quite possibly limit an actor's understanding of the text. Using this technique an actor is disallowed from choosing in what manner to say the words until such time as he or she has spoken them repeatedly and thereby gleaned detailed meaning from the words themselves. Often, I can discover the detail and nuance of the writing, only through this sort of slow, methodical chanting. Then, when I progress in my spoken text exploration into speaking the lines with inflection —-with varied speed, pitch and volume-the understanding of the lines that I gained from chanting them without inflection informs the way in which I speak them. Effectively, the vocal text exploration technique of chanting the lines 
has fueled my understanding of the meaning of the words and why and in what way the character says them. In short, the technique has allowed me to tap into the Aquifer of Impulse. 


\section{On Movement:}

Physical Embodiment of Gesture and Movement as

Contributor to Aquifer of Impulse

Since actors can and do use their bodies as creative sources and developers of performance content, how does an actor, through technique, develop and shape a performance that most effectively conveys his or her interpretation? What techniques do I utilize to enable my body to inform me of what choices to make in rehearsal and performance, and how do I further utilize technique to shape my performance so that it most accurately conveys my interpretation to an audience?

The imitation of the actor-mime demands first of all very precise observation of the gestures, attitudes and movements of mankind and of nature, which will then serve as language for the mime's own poetry in being transposed. For the mime it is a question of seizing the apparent life of the real in order to make it his own, to replay it within himself, in order then to play it for an audience following his own vision.

Jacques Lecoq, Theatre of Movement and Gesture (69)

Here Lecoq summarizes the actor's job in the physical creation of character: the actor observes physical behaviors from the real world and then, in a form of imitation, utilizes those behaviors to display to an audience his or her interpretation of a role. When restated, the quote seems rather straightforward; however, Lecoq's meaning is rather detailed and nuanced. Importantly, Lecoq points to the "apparent" nature of the "life of the real" which is replayed for an audience. For it is the apparent, the perceived, that is valuable for an actor. As he suggests, actors 
must perceive what meanings are conveyed by gestures and movement in reality and then embody and take ownership of those actions so that they may be played for an audience in order to convey meaning following the actor's vision. Lecoq stops short of overtly stating that the actions themselves create the actor's vision, but implied in his statement is that the embodiment of the actions, the replaying of the actions within oneself, actually creates understanding in the actor. It allows the actor to create an interpretation of the movement or gesture. The "gestures, attitudes and movements" act first as the source of the actor's interpretation (while the actor explores the embodiment of the action) and also ultimately serves (during performance) as the end product that conveys meaning to an audience.

In his book Embodied Acting: What Neuroscience Tells us About Performance, Rick Kemp points to modern scientific evidence that retrospectively supports the theoretical and practical work of Lecoq and other theatre practitioners who advocated physical approaches to acting. Kemp discusses how the work of social scientists, including cognitive linguist David McNeill, reveals that gesture and movement contribute not only to the communication that is sent by a communicator but also that the movement actually influences the communicator's understanding of what is being expressed;

McNeill develops his analysis of the relationship between gesture and speech in Gesture and Thought (2005), arguing for a new conception of language, viewing it as an imagery-language dialectic, in which gestures provide imagery ... McNeill posits that gestures are key ingredients in an "imagerylanguage dialectic" that fuels both speech and thought. Gesture is an integral 
component of language in this conception, not merely an accompaniment to, or ornament of, speech but synchronous and co-expressive with it ... here, gestures are shown to be active participants in both speaking and thinking... This analysis is developed from close observation of the synchrony of speech forms and gestures that suggests that they are co-expressive of the same underlying thought unit. (Kemp 66)

Like Lecoq, McNeill is observing real behaviors that are conveying information to both the observer and the communicator. Kemp goes on to suggest that these findings of the jointure of gesture, speech and idea can be reverse-engineered to apply to the reading of a script in preparation for performance. While actors who are familiar with a Stanislavskian form of script analysis think of objectives and tactics, McNeill's empirically derived theory offers a reliable way of analyzing dialogue that depends on the identification of units of thought, ... which gives the actor a useful tool in textual analysis, and facilitates the subsequent transformation of written language into embodied speech. (Kemp 67)

As Kemp implies, and Lecoq doubtless knew, through supposition about what a character's physical actions might be and the subsequent exploration of the embodiment of those actions, an actor can use his or her body to discover meaning that underlies a character's speech and ideas. In the same way a playwright provides the words that an actor inhabits in order to create a character-to Reverse Ratiocinate a role-so, too, can the gestures and movement of a character serve as 
the blueprint from which an actor creates an Aquifer of Impulse. And, again like the spoken words, the movement serves not only as the source of the actor's creation of impulses, but also (in performance) as the manifestation of the impulses. In both cases, the actor draws upon this Aquifer while in performance to wholly enact the ideas, words and actions of the character.

In pursuit of my MFA, I have learned and implemented myriad physical acting techniques that have provided opportunities for practical exploration of movement as contributor to the Aquifer of Impulse. One such case emerged as I was working with character masks in an acting class. I had chosen to work in several sessions with a very youthful looking mask that was rather small. The mask itself slightly constricted my vision and forced me to squint a little bit. I had not set out to explore any physical technique overtly, but it soon became clear to me that the mask, which I later called “Frat Dude," imposed a physical constraint on my body and the way I moved. Because I was forced to squint I felt like my mental focus, the center of the character's physical and mental existence, was located inside my eyeballs. It made me retreat inward. I became hesitant to take action and mentally slow. [For the record, even I think this is weird. Weird but true. You're weird, dude. Who are you, Michael Chekhov? At any rate...] The physical embodiment of the character was creating ideas and feelings. In short, it was contributing to the Aquifer.

I pursued the exploration of these physical constraints and the accompanying mental state and found that with effort, the character could focus on points beyond himself and seemed always to exist in one or the other of these two different states: 
the internal eye focus on the "self" and the external focus on the "other." It eventually seemed akin to Circles of Attention as conceived by Stanislavski. I could feel that my body and brain were closing in physically and mentally to an internal focus as I squinted. Not only was my body communicating to me, but it became apparent through self-observation (in this case via a mirror) that my body was also, through gesture, communicating information to any potential observer. In the inward focused state my movement and physical expression indicated that I was concerned with self, perhaps as if I was on the verge of some profound idea that was about to spring forth from my brain. On the other hand, as I focused on the "other" I could feel (and see) the focus of my physical being expanding to include a larger physical space. My body and physical attitude took up more space. I was "seeing" a bigger physical area and I felt more inclined to engage with the surroundings. I have since come to understand for myself these feelings—both physical and mental-as my understanding of the technique of Circles of Attention and can utilize them as a physical technique that focuses my eyes and facial expression and by extension my gestures and attitudes either internally or externally. Through the conscious manipulation of these mental and physical states I can convey to an audience meaning about a character's focus and relationship to "self" and "other" and even intention.

In retrospect I recall playing a character in rehearsals for Vinegar Tom at the University of Virginia in the spring of 2012, wherein the director told me to "listen more." I thought that I was genuinely listening to the other actor/character, but what I didn't realize was that because my character was highly concerned about his 
own ideas in the scene, my physical and mental focal point was essentially that of "Frat Dude's" internal focus; directed inward. This internal mental focus manifested (unintentionally) in physical movement and gesture that was interpreted by the director as not being focused on the "other." Whereas I was interpreting my character as listening fully to the other character, I was not accurately conveying my interpretation of the character. I was not utilizing a proper technique to do so. Had I been in command of this technique of Circles of Attention as I now understand it, I would have been able to adjust my performance to address the director's critique more accurately.

Of course, any of the physical techniques I use does not occur merely in isolation. As born out in the research of Richard Kemp, the physical action is inextricably linked with the ideas and the words of a character. In the creation of the character of Jean in Rhinoceros, at the University of Virginia in the Fall of 2012, I was particularly utilizing Laban Effort Actions, a technique of creating character and performance based on moving the body in particular ways, such as finding how slow or fast a character generally moves. In this case, this technique was enhanced and influenced by many factors including the play's director, my script analysis, and my vocal choices. In the first act Jean is very proper and rather uptight; highly concerned with appearances and particularities of all sorts. In addition, the director had asked that we consider the style of 1930's and 40's film comedies as a source for inspiration of the world of the play. The quick banter of the script and of those films coupled with Jean's fastidious nature seemed to suggest the Laban elements of Suddenness and Lightness. 
Such Laban qualities seemed a good place to begin physical exploration of character, particularly in light of the contrast it might show between Jean and Berenger, for whom Jean acts as foil. To quote Lecoq again: having made my "observation of the gestures, attitudes and movements of mankind and of nature," I set about to Reverse-Ratiocinate them and make them "serve as language for the mime's own poetry in being transposed" (69). Early in rehearsal I began to explore gestures and movement with a Laban Lightness and Suddenness in mind. As if automatically, I adopted pursed lips and very small, quick hand gestures that were mostly right in front of my upper chest, with my palms turned out facing directly in front of me. In addition to the speed and crispness of the gestures, Jean's speech was very fast and very clean; in fact, as quick and crisp as I could possibly execute. I have no doubt that my movement, with its quickness that I was striving for, informed my thought and speech and vice versa. I was experiencing the coupling of gesture and thought as described in McNeill's "imagery-language dialectic." But my work on the role was not finished. In the second act Jean progressively transforms into a rhinoceros, so the challenge became defining physically (and vocally and mentally) what constituted the alternate state of being. With Laban in mind I played all the movement of the "Rhino Jean" as Strong versus the previously Light Jean. I also held my head out very forward and down to mimic the physicality of a rhinoceros. This radically altered my eye line and vision and more or less disallowed the placement of my arms in their previous "Jean" position in front of my chest. In addition to the physical shift, I experienced a mental shift. I no longer felt as smart and began to feel the inclination to be agitated. The script of course, 
indicates these feelings, so I knew that the physical attitudes and gestures were enabling me to fulfill the needs of the text. I was also able to play these two contrasting physical and mental states to comical effect by popping from one to the other almost instantaneously. By embodying each state physically and mentally as fully as possible-what Maria Aitken would call "slaloming" between the two states (117) - I was able to convey to the audience a character that was completely losing control of reality in a surreal world. My physical choices had informed my vocals and thoughts and all in tandem were effectively conveying my interpretation of the character. 
On The Technique of Acting:

The Importance of Being Earnest

Or

(When Necessary)

The Importance of Being Something Other Than Earnest

in Favor of Being Effective

And

The Wisdom to Know the Difference

After years of study and contemplation of acting and many acting techniques, and in coming to understand acting as Re-Reversed, Comingled Ratiocination and the utilization of the Aquifer of Impulse, I have realized that acting, or rather, effective, clear acting-what I will define as that which conveys the actor's intended portrayal of character to an audience-is not founded merely on the technique on which it is built, but in large part on the ability of an actor to recognize which choices, and indeed non-choices, are most effective in conveying the intended meaning. The quality of an actor's performance is not defined by the technique with which it is created, nor in many cases is it completely derived from that technique, but, rather, it is defined by the combination of the quality of the actor's interpretation and the effectiveness of the actor's choices in conveying that interpretation to an audience. Depending on the actor, the performance is derived from the use of a wide variety of techniques and, indeed non-techniques including intuitive behavior and physical appearance. The quality, or the lack thereof, of a performance is in the eye and the ear of the beholder: the audience. A skilled actor 
is not the actor who behaves truthfully, but the actor who appears to be behaving in the truest (effectively, the most compelling, dynamic or empathy-generating) way, and the actor who successfully conveys the intended choices to an audience.

The process of acting a role is one of building an accurate conveyance of the actor's understanding of a character and a script. (For purposes of this discussion a script means any predetermined performance blueprint, linguistic or otherwise). An actor needs to construct a role so that the performance will lead an audience toward the intended interpretation of the role. Granted, that interpretation may include intentional ambiguities and even contradictions. However, in most cases an actor is attempting in any given instance to convey specific meaning through his or her performance. In most cases an actor's performance is guided by a director who is in large part responsible for shaping the final product and who acts as arbiter of what constitutes effective conveyance of meaning to an audience. But rather than relying on a director or other artistic collaborators to enable an actor to make strong choices, it behooves an actor, of his or her own accord, to create a portrayal that most clearly conveys his or her interpretations of the script—sans director, sans acting coach, sans everything... except his or her own self-assessment and technique. These strong choices are then incorporated into rehearsals and production enabling the other collaborators to benefit from the work done by such an actor and to shape that portrayal to fit the needs of the production.

With that in mind, the actor's process in creation of a role is broadly constructed of the following steps:

1. The actor makes decisions about the script and the character and 
experiments with ways of playing the scene by implementing various techniques. The particular techniques and the range of techniques employed for any particular purpose, of course, vary widely depending on the experience and skill of the actor, as well as the particular style or demands of the script.

2. The actor deems some specific techniques of playing the script to be most valid and employs them in performance.

After several years of teaching beginning actors, and through observation of my own acting process, I've observed that step 2 is where many actors, including most beginners, reach a point of conclusion. At this phase they have more or less done their job and, in many cases, can achieve a high level of success in performance. But most actors lack the skills to assess and advance their work until such time as an outside observer suggests how their performance could be improved. What more or less does not occur to the inexperienced actor are the next steps, which are more complex and require different, more sophisticated skills. These are the skills toward which actors, particularly student actors, must strive. (In the following chapter I will further discuss the challenges that face the student actor).

3. The actor begin to become self aware enough to identify specifically what his or her behavior as the character will actually convey to an audience. In many cases, the behavior, or elements thereof, run counter to an effective conveyance of the actor's interpretation. Often, in spite of an actor's implementation of technique, the performance-what the actor is actually 
doing with his or her body or voice-is not conveying what the actor wants. For example, when concerned with the playing of an intense moment of a scene, an actor may lack a clarity of vocal communication that undermines the story the actor is trying to tell through the performance.

4. The actor reexamines those techniques and implements different or additional techniques to alter and craft the performance to better reflect his or her interpretation of the script.

5. The actor weighs, as objectively as possible, the relative merits of the choices revealed by these techniques and, specifically, to what degree the manifestations of those choices serve to convey his or her interpretation.

6. The actor implements those techniques and choices that most effectively convey his or her interpretation of the script.

7. The actor presents those choices to a director and other artistic collaborators and incorporates feedback so that a performance will most accurately convey the artistic vision of the actor as well as the actor's collaborative partners.

In light of this understanding, how do I progress through the advanced steps and arrive at an accurate conveyance of my interpretation? An example of an exploration of how to construct the best performance by choosing the right information to convey to the audience can be found in my preparation of a Macbeth soliloquy that I rehearsed and performed for voice class and now use for auditions.

At the end of the soliloquy Macbeth says: "come fate into the list and champion me to the utterance" which can mean A: 'come fate into the arena and fight me oneon-one to the death' (in this interpretation Macbeth is taking fate on directly) or B: 
'come fate into the arena and fight on my behalf against the prophesy of the sisters (in this interpretation the "utterance" means the prophesy they spoke, which means Macbeth is invoking fate to intercede on his behalf and protect him.) Those two meanings are almost opposites and, because Shakespeare is a genius, both meanings are contained in that statement, and both are valid interpretations and ways of playing the soliloquy. In a coaching session, my professor pointed out to me the second interpretation, which hadn't occurred to me. I had thought of and played only the first. And I thought, "Well, I like my interpretation, although hers is valid." Later I realized that the relevant factor in creating the best performance is not which interpretation I am playing, but rather the effect that is conveyed by the playing of either of those choices. I need to choose the one that gets me to use my body and voice and mind to convey the appropriate information to the audience. They have no idea, nor do they care, about my interpretation of the line; they don't know or care which part of the Aquifer of Impulse I drew the lines from; they don't know or care if I am playing an objective or a tactic or a Laban Effort Action. They witness only the manifestation of those choices, the final product of what I have chosen to show them. My responsibility as an actor is to identify and execute the technique that most accurately conveys what I want the audience to think about the character.

If I decide that Macbeth is challenging fate and has already resolved to fight to the death, then I would likely choose the "fate, fight me one-on-one to the death" to make me seem aggressive and resolved. The performance would proceed with the audience invited to think that I am doomed to my fate and will act out the 
horrific tale having chosen to never look back. On the other hand, if I thought that Macbeth was scared and trapped and trying to escape, I would likely choose the "fate, fight on my behalf" interpretation, to seem desperate and maybe crazed, and the rest of the performance would look like a weak character desperately hanging on. Then again, the manifestations of playing the line in those two ways might not parallel the interpretations; they might not read to an audience as what my preconceived ideas are. My job as the actor is not to play the line the way I imagine it should be played, but to explore numerous possibilities, assess those choices, implement further technique to craft and shape the performance, and ultimately perform the choices that best present the story I choose to tell. 


\section{On Teaching Acting: \\ Lessons From the Classroom}

After watching so many beginning acting students perform in class and in production, it becomes clear that, frequently, an actor has made clear choices about how to play a moment of a performance, scene or a whole role; and is able to articulate those choices verbally or in writing; and, is executing those choices in performance, but remains largely unaware of much of what he or she is actually conveying to an audience through his or her voice and body. For example, many beginning actors exhibit habitual posture or gesture that undermines a performance by sending an audience unintended information about the character. And, even if an actor is to some extent aware of what he or she is conveying, often actors are unable to effectively shape a performance to reflect his or her interpretation and accurately convey, through their behaviors onstage, the choices they have made. In a simple example, an actor may not use enough volume and articulation to effectively convey the character's words to an audience, despite the fact that the actor was utilizing an accurate understanding of acting technique, such as playing an objective.

This discrepancy between an actor's attempt to convey interpretation and what is actually conveyed is something all experienced actors have encountered firsthand, having played out the following scene in rehearsal:

THE DIRECTOR: How about playing that line as __ $\mathrm{X} \_$.

THE ACTOR: I was playing __ __ but obviously it didn't read, so I'll try something else so that it might read as __ $\mathrm{X} \ldots$. 
(THE ACTOR quickly racks brain for why __ _ _ didn't read and scans mental Rolodex of acting techniques to find some way of playing the moment to make____ read. Depending on who is playing THE ACTOR, the next time through the scene, A) the technique is there!! and renders a performance that manifests in the Director's interpretation as __ __ (hooray!) or, $B$ ) if the Rolodex comes up insufficient, THE ACTOR implements the technique that will hopefully work, which results in a minor improvement and THE DIRECTOR thinks something like "Well that's still not____ but it's better, so..." THE STAGE MANAGER: We need to take a 10 and move on to the next scene. Fin

As student actors prepare for a performance of a scene or a monologue, and I subsequently coach them, there are numerous challenges for them, and me, as we try to negotiate what ideas and techniques will help them effectively convey their interpretation of a character to an audience.

Naturally, there are pitfalls as I attempt to turn a student actor towards better self-assessment in rehearsal and performance and to introduce them to new acting techniques. I can become too directorial and merely prompt them to improve the scene or monologue without really providing them lasting tools to understand the theories or concepts they may have studied but are unable to effectively implement. But the even more challenging aspect of such a teaching moment is to convey to them some sort of method or technique or techniques, by which they might better observe and analyze themselves, and ultimately utilize such analysis to 
make better choices earlier and more frequently in their processes.

Just like the Acting I students, I, as an experienced actor, am continuing to build an ever-increasing range of techniques that can be utilized for the purposes of clarifying my interpretations of roles. In the case of most Acting I students, the skills are very basic, and anyone with a lot of experience and technique could look at their performances and offer some elementary feedback to generate improvements. "Let's 'raise the stakes'," I might say. "If your character allows the other character to walk out the door then you'll never see them again and everything you worked your whole life for will be for naught." Why then, the beginning actor will make a different, probably bolder and better choice and the whole class will agree that "raising the stakes" worked. I see this in students all the time. But this sort of onetime fix does not provide the students with sophisticated tools to assess themselves and come to implement the appropriate technique that will improve a performance next time.

To examine this more closely, I'll mention the instance that got me thinking about this idea. It came not while I was teaching, but while watching one of my undergraduate classmates in our Musical Theatre Performance class. As soon as I saw this particular performance, it immediately became clear to me that the same sort of thing happens frequently with inexperienced actors. I've seen it over and over again in Acting I. The student in question was performing a bigger-than-life character, singing a song wherein the character was weighing the relative merits of two courses of action and, by the end of the song, had chosen, with much conviction, one path over the other. And, even now as I write the scene description, generic as 
it is, the technique that I would certainly deploy right away is that of Maria Aitken's "slaloming" (117). The theory goes that the more an actor can inhabit one state of being (for example carefree love), the more effectively it will convey the choice with which a character is faced and thereby communicate the inner conflict or hypocrisy or surprise when the character switches to an alternative state of being (for example denial of love). If I were to read that text it would practically scream Slalom! at me, and I would attempt to play the two different states the character was in as he considered which of the two options to pursue: to maintain the safe status quo or to give in to true love-no small matter.

But, in this, case the undergraduate who was performing the scene was not performing this song with any particular conviction. It appeared there was no slaloming at all, or at least no slaloms were conveyed to the audience. The actor conveyed no sign of inner conflict or desperation to figure out her plight. In addition, the big moment of decision, the climax, at the end of the song, which was clearly indicated by the music and lyrics, was not an escalation; nothing in her performance was reading to the audience as an important moment to the audience. Her gestures seemed half-hearted and her gaze seemed to reach out only about four feet in front of her face, even though the character was screaming to the heights that she had at last realized what true love was. This particular actor was a person who would soon be graduating from college, who was a good singer, who had taken at least two performances classes and acted in numerous productions while enrolled. She was conversant in her character's objectives and obstacles. She was clearly well versed in basic acting techniques and presumably utilizing them, and yet she lacked 
the acting technique to assess what she was actually conveying to the audience and/or the ability to craft her performance to convey her interpretation.

Immediately after her classroom performance, the graduate actors started to chime in with some feedback to the effect of: "the different states that your character is occupying as she weighs these option is just not reading;" "If your character likes the safe status quo then really find that the safety is comforting or perhaps so familiar that you can't let go;" or "at the end of the song her love has to send her soaring through the sky and you looked only big enough for the rehearsal room." Slaloming and Circles of Attention were the techniques that the song called for. At the end of the song, she should have expanded her gaze and physical attitude to encompass the whole universe and then it would read as true love and convey the story of her interpretation of the role. I even thought that if I were coaching this performance, I could give her some ideas about techniques to make this happen. Even if the student had no familiarity with Slaloming or Circles of Attention as techniques, a good director might offer an assessment of her performance that suggested she convey the dynamic emotion of the script by encouraging her character to go more in one direction towards the safety of the status quo and then more in the other direction towards being lost in the love, effectively leading her through the Slalom. And, similarly, that good director might suggest she focus her eyes and gestures farther out and more specifically, maybe even longingly, to the man she loved, who is perhaps beyond the third balcony. With both these directions, a director or teacher would cultivate new choices that would read as stronger acting. Then all would be well for the time being. She would at least have a 
one-time improvement. And, if she were quick on the uptake, she might take away a few general pointers from the experience. Even better, if the director had some time to explain the theory of that technique and give her a practical experience utilizing it, the actor might be even more able to take it into future roles.

Naturally, as I watched her performance, I thought of myself performing this song. Surely, I thought, if it were me, I would know what technique to utilize. Just by living with the text for a little while. The Slaloms and Circles of Attention would almost certainly be obvious soon enough. I would completely occupy the two different states in turn and deftly toggle between the two; Maria Aitken would be proud. As a bonus, because I was so committed to the acting technique, my vocals and breath would perhaps be strengthened and more nuanced, and, with my experience, I would perceive this and work to cultivate it. At the end of the song, I would transition from an internal focus out toward the heavens, and I would effectively convey my interpretation. Or would I? Would I as the performer effectively identify and utilize those techniques that so plainly would have improved my classmate's performance? Or for that matter, would I, as I act in any given role, utilize the techniques that would improve the performances of so many Acting I students that lack the technique and experience to self assess and convey what they are attempting to play in any given scene?

That's the question. As an outside eye I can clearly see a number of things that can improve these beginners' performances. Increasingly I am able to identify what about a performance is not reading and why a performance does not convey what the actor is playing. I now have a broad enough knowledge of techniques so 
that, as I watch a mediocre performance, I can identify a specific remedy or amendment that will help improve it and/or give an actor more options to make better choices. But the question remains: How readily and how well do I do this for my own performances? As I watched my classmate sing that song I thought, "If I were performing this, I'm sure I would be Slaloming like crazy in during that song, but would I be self aware enough to know that my focus and gesture were not conveying what I was playing?"

Undoubtedly, I continue to progress in this area. I am increasingly aware of my vocal choices and technique, and I am learning by observing less experienced students. In fact, the song I sang in that class was much the same form as the song I've discussed: lots of specific Slaloming followed by a decision to take action made with strong conviction. Using my classmate's performance as a model I know that, in my own performance, I was implementing the techniques that I would have prescribed to her and, presumably, it improved my performance. But the question remains: how much did I improve because of these observations, and how aware am I of when, and in what manner, I should implement certain specific techniques in my own performance? This is the challenge I'll continue to face. 


\section{Work Cited}

Aitken, Maria. Style: Acting in High Comedy. New York: Applause Theater and Cinema Books, 1996. Print.

Brook, Peter. The Empty Space. New York: Touchstone, 1968. Print.

Kemp, Richard. Embodied Acting: What Neuroscience Tells Us About Performance. New York: Routledge, 2010. Print.

Lecoq, Jacques. Theatre of Movement and Gesture. New York: Routledge, 2006. Print. 
Appendix: Video Supplement

In addition to the written portion of this thesis, there is a supporting video supplement as evidence of my work. There are performances of two Shakespeare monologues: Petruchio and Macbeth. The Macbeth monologue is the soliloquy mentioned earlier in this thesis and which I originally approached and memorized solely by the technique of chanting, before utilizing various other vocal acting approaches and other techniques, such as shifting between internal and external Circles of Attention. These sorts of vocal and physical methods enabled me to find a deep, personal connection to the text and informed the way I understand and perform it. These techniques and many others that I studied in pursuit of my MFA act as the foundation of my concepts of Re-Reversed, Comingled Ratiocination and the Aquifer of Impulse. In the rehearsal of these monologues I familiarized myself with the words by speaking them repeatedly in an attempt to understand them as the characters do, and I also developed gestures and movements that, as they are executed, both inform the character/me and also the audience, again according to my techniques and theories.

Also included in the video supplement is a video of a workshop production of The Swiss Swap: A Martin and Margaret Adventure, a farce that I co-wrote and codirected with my fellow MFA candidate Amaree Cluff. As the writers, directors, and two of the actors, Amaree and I were particularly concerned with creating a specific aesthetic that was founded on our understanding of the techniques of how an actor's voice, body, and mind — and indeed the confluence of the three-can be utilized as 
the source material for creation of character and story and also manipulated as the method of conveying that information to an audience. 